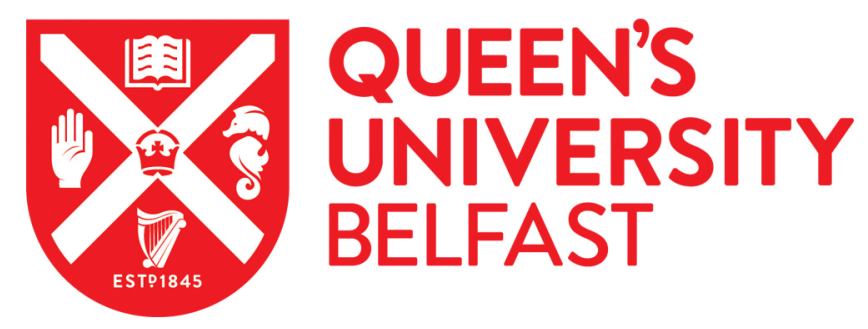

\title{
Serum cholesterol levels and tumor growth in a PTEN-null transgenic mouse model of prostate cancer
}

Allott, E. H., Masko, E. M., Freedland, A. R., Macias, E., Pelton, K., Solomon, K. R., Mostaghel, E. A., Thomas, G. V., Pizzo, S. V., Freeman, M. R., \& Freedland, S. J. (2018). Serum cholesterol levels and tumor growth in a PTEN-null transgenic mouse model of prostate cancer. Prostate Cancer and Prostatic Diseases, 21(2), $196-203$. https://doi.org/10.1038/s41391-018-0045-x

Published in:

Prostate Cancer and Prostatic Diseases

Document Version:

Peer reviewed version

Queen's University Belfast - Research Portal:

Link to publication record in Queen's University Belfast Research Portal

Publisher rights

(C) 2018 Springer Nature Limited. All rights reserved.

This work is made available online in accordance with the publisher's policies. Please refer to any applicable terms of use of the publisher.

\section{General rights}

Copyright for the publications made accessible via the Queen's University Belfast Research Portal is retained by the author(s) and / or other copyright owners and it is a condition of accessing these publications that users recognise and abide by the legal requirements associated with these rights.

Take down policy

The Research Portal is Queen's institutional repository that provides access to Queen's research output. Every effort has been made to ensure that content in the Research Portal does not infringe any person's rights, or applicable UK laws. If you discover content in the Research Portal that you believe breaches copyright or violates any law, please contact openaccess@qub.ac.uk. 


\section{Serum cholesterol levels and tumor growth in a PTEN-null transgenic mouse model of prostate cancer}

Emma H. Allott ${ }^{1}$, Elizabeth M. Masko², Alexis R. Freedland ${ }^{3}$, Everardo Macias ${ }^{3}$, Kristine Pelton ${ }^{4}$, Keith R. Solomon ${ }^{5}$, Elahe A. Mostaghel ${ }^{6,7}$, George V. Thomas ${ }^{8,9}$, Salvatore V. Pizzo ${ }^{10}$, Michael R. Freeman ${ }^{3}$, Stephen J. Freedland $d^{3,11}$

${ }^{1}$ Department of Nutrition, University of North Carolina at Chapel Hill, Chapel Hill, NC ${ }^{2}$ Department of Surgery, Duke University Medical Center, Durham, NC

${ }^{3}$ Department of Surgery, Samuel Oschin Comprehensive Cancer Institute, Cedars-Sinai Medical Center, Los Angeles, CA

${ }^{4}$ Department of Medical Oncology, Dana-Farber Cancer Institute, Boston, MA

${ }^{5}$ The Urological Diseases Research Center, Boston Children's Hospital, Boston, MA (current address: Applied Photophysics, Beverly, MA)

${ }^{6}$ Division of Oncology, Department of Medicine, University of Washington, Seattle, WA

${ }^{7}$ Clinical Research Division, Fred Hutchinson Cancer Research Center, Seattle, WA

${ }^{8}$ Knight Cancer Institute, Oregon Health and Science University, Portland, OR

${ }^{9}$ Pathology and Laboratory Medicine, Oregon Health and Science University, Portland OR

${ }^{10}$ Department of Pathology, Duke University Medical Center, Durham, NC

${ }^{11}$ Division of Urology, Veterans Affairs Medical Center, Durham, NC

Running title: Cholesterol, androgens and prostate cancer

Keywords: androgen, cholesterol, obesity, prostate cancer, PTEN, transgenic, Western diet

Financial support: EHA: American Institute for Cancer Research; SJF: NIH Grant 1-R01-

CA131235-01A1 and NIH 1K24CA160653 
Corresponding author: Dr. Stephen J Freedland; Mailing address: Cedars-Sinai Medical Center, 8635 West 3rd Street, Suite 1070W, Los Angeles, CA 90048, USA; Tel: 310-423-3497; Fax: 310-423-4711; Email: stephen.freedland@cshs.org

Word count: 2454 (excluding abstract and references); Abstract count: 300 


\begin{abstract}
Background: Some, but not all, epidemiologic evidence supports a role for cholesterol, the precursor for steroid hormone synthesis, in prostate cancer. Using a PTEN-null transgenic mouse model of prostate cancer, we tested the effect of modifying serum cholesterol levels on prostate tumor development and growth. We hypothesized that serum cholesterol reduction would lower tumor androgens and slow prostate cancer growth.
\end{abstract}

Methods: PTEN loxP/loxP-Cre ${ }^{+}$mice consuming ad libitum high fat, high cholesterol diets $(40 \%$ fat, $1.25 \%$ cholesterol) were randomized after weaning to receive the cholesterol uptake inhibitor, ezetimibe (Zetia; $30 \mathrm{mg} / \mathrm{kg}$ diet), or no intervention, and sacrificed at 2, 3 or 4 months of age. Serum cholesterol and testosterone were measured by ELISA and intraprostatic androgens by mass spectrometry. Prostate histology was graded, and proliferation and apoptosis in tumor epithelium and stroma was assessed by Ki67 and TUNEL, respectively.

Results: Zetia-treated mice had lower serum cholesterol at 4 months $(p=0.031)$. Serum cholesterol was positively correlated with prostate weight $(p=0.033)$ and tumor epithelial proliferation $(p=0.069)$, and negatively correlated with tumor epithelial apoptosis $(p=0.004)$, but unrelated to body weight $(p=0.195)$. Tumor stromal cell proliferation was reduced in the Zetia group $(p=0.010)$. Increased serum cholesterol at 4 months was associated with elevated intraprostatic DHEA, testosterone and androstenedione $(p=0.043, p=0.074, p=0.031$, respectively). However, cholesterol lowering did not significantly affect adenocarcinoma development at 2,3 or 4 months of age $(0 \%, 78 \%, 100 \%$ in Zetia-treated vs. $0 \%, 80 \%, 100 \%$ in mice not receiving Zetia).

Conclusions: Though serum cholesterol reduction did not significantly affect the rate of adenocarcinoma development in the PTEN-null transgenic mouse model of prostate cancer, it lowered intraprostatic androgens and slowed tumor growth. These findings support a role for 
serum cholesterol in promoting prostate cancer growth, potentially via enhanced tumor androgen signaling, and may provide new insight into cholesterol-lowering interventions for prostate cancer treatment. 


\section{Introduction}

Obesity is associated with increased risk of aggressive prostate cancer and elevated prostate cancer-specific mortality. ${ }^{1}$ Currently, it is estimated that one in five US adults have uncontrolled hypercholesterolemia, a metabolic disorder associated with obesity. ${ }^{2}$ While some epidemiologic evidence supports an association between hypercholesterolemia and increased incidence of aggressive prostate cancer, ${ }^{3-6}$ a recent meta-analysis found no significant association between serum cholesterol and either overall or high-grade disease. ${ }^{7}$ Several studies reported positive associations between hypercholesterolemia and increased risk of prostate cancer recurrence ${ }^{8,9}$ and mortality, ${ }^{10}$ yet others found no associations or even inverse relationships. ${ }^{11,12}$ Statins, a group of widely-prescribed cholesterol-lowering drugs, are associated with lower risk of aggressive prostate cancer, ${ }^{13}$ decreased prostate cancer recurrence ${ }^{14}$ and reduced mortality. ${ }^{15}$ However, it is not clear whether this effect is due to direct effects of the statin itself, or indirect effects mediated via cholesterol-lowering. ${ }^{16}$ As such, the true biological potential of targeting serum cholesterol to slow prostate cancer growth and progression is promising, but unclear.

Cholesterol is the precursor for de novo steroidogenesis, which is crucial for prostate cancer growth. ${ }^{17}$ Indeed, serum cholesterol reduction has been demonstrated to lower intratumoral androgen levels and slow tumor growth in a xenograft mouse model of human prostate cancer. ${ }^{18,19}$ However, the effect of cholesterol reduction on prostate cancer growth has never been tested in a transgenic model, which enables assessment of tumor growth within the native prostate microenvironment. The objective of this study was to determine the effect of modifying serum cholesterol levels on tumor development and growth in an obese transgenic mouse model of prostate cancer. Given that PTEN is among the most frequently mutated/deleted genes in human prostate cancer, ${ }^{20}$ we selected the PTEN-null mouse model for this study. We hypothesized that reduction of serum cholesterol levels would lower tumor androgens and slow tumor growth. 


\section{Materials and Methods}

\section{Animal study design}

All animal protocols were approved by Duke University Institutional Animal Care and Use Committee. Prostate-specific homozygous deletion of PTEN was achieved by crossing PTEN $N^{\operatorname{loxp} / l o x p}$ mice with mice of the ARR2Probasin-cre transgenic line PB-Cre4, where Cre recombinase is under the control of a modified rat prostate-specific probasin promoter, as previously reported. ${ }^{20}$ Tumor development is well characterized in this mouse model, with development of prostatic hyperplasia by 4 weeks of age, mouse prostate intraepithelial neoplasia (mPIN) by 6 weeks of age, and invasive prostate adenocarcinoma by 9 weeks of age.$^{20}$ Breeding pairs were obtained from the National Institutes of Health Mutant Mouse Resource and Research Center (NIH MMRRC) on a C57BL/6 genetic background and PTEN/oxp/loxp_Cre ${ }^{+}$(PTEN-null) mice were bred in-house. Diets were prepared by Research Diets Inc. (New Brunswick, NJ), and sterilized by irradiation. At approximately 30 days of age, 92 male PTEN-null mice were randomized to receive a) ad libitum high-fat high-cholesterol (HFHC, $\mathrm{n}=45 ; 40 \mathrm{kcal} \%$ fat, $43 \mathrm{kcal} \%$ carbohydrate, $17 \mathrm{kcal} \%$ protein, $1.25 \%$ cholesterol) or b) ad libitum $\mathrm{HFHC}$ diet with ezetimibe, a cholesterol uptake inhibitor (Zetia, $\mathrm{n}=47 ; \mathrm{HFHC}+30 \mathrm{mg} / \mathrm{kg}$ ezetimibe; Supplementary Table S1). All mice were group-housed, and body mass and average food consumption were measured biweekly for the study duration. Mice were euthanized using a lethal dose of ketamine and xylazine followed by bilateral thoracotomy at two ( $n=12$ per diet group), three ( $n=10$ per diet group) and four months of age (HFHC, $n=23$ and Zetia, $n=25$ ). Blood was obtained via cardiac puncture immediately following euthanasia, allowed to clot at room temperature for 30 minutes, and centrifuged at 13,000 rpm for 90 seconds. Serum was collected and stored at $-80^{\circ} \mathrm{C}$ for analyses. The entire genitourinary (GU) tract was removed intact from PTEN mice. Seminal vesicles, bladder and fat were removed, and the prostate was weighed and bisected along the sagittal plane. One half of the prostate was flash frozen in liquid 
nitrogen and stored at $-80^{\circ} \mathrm{C}$, while the other was fixed in $10 \%$ formalin for 48 hours and then paraffin embedded. The formalin-fixed prostate was oriented within the paraffin block to ensure representation of all prostate lobes (i.e., dorsal, ventral and anterior) on the resulting slides.

\section{Histologic analyses}

Formalin-fixed paraffin-embedded prostate tissue was cut to generate three $4 \mu \mathrm{m}$ sections, each separated by $50 \mu \mathrm{m}$, and stained with hematoxylin and eosin (H\&E) for histopathologic evaluation. Slides were scanned using an Aperio ScanScope and grading of H\&Es was conducted by a single investigator (EHA) blinded to dietary group, under the guidance of a board-certified pathologist (GVT). All prostate lobes were graded across all three sections, and lesions (mPIN, invasive and intracystic adenocarcinoma) were noted as present vs. absent. Intracystic lesions were found only in the anterior lobe, while mPIN and invasive adenocarcinoma were found in all lobes.

Serial $4 \mu \mathrm{m}$ sections were cut and stained with antibodies against Ki67 (Thermo Scientific, Rockford, IL) and TUNEL (ApopTag® Plus Peroxidase In Situ Apoptosis Kit; Millipore Inc., Billerica, MA) to assess proliferation and apoptosis, respectively, in regions of invasive adenocarcinoma across all prostate lobes. These analyses were restricted to mice 4 months of age. Ki67 and TUNEL H score was quantified within epithelium and stroma separately using a digital pathology nuclear algorithm (Definiens Tissue Studioß) at the Translational Pathology Core, University of North Carolina at Chapel Hill. In order to assess these markers in invasive adenocarcinoma regions only, areas of normal prostate tissue were manually excluded from analysis, and areas of necrosis and cellular debris (including intracystic lesions, where present) were excluded using the digital algorithm. As such, in mice with intracystic lesions, invasive adenocarcinoma in the area surrounding the intracystic lesion in the anterior lobe, along with 
invasive adenocarcinoma in ventral and dorsal lobes, was analyzed for Ki67 and TUNEL staining.

\section{Serum and prostate analyses}

All serum parameters were measured at 4 months of age. To assess liver health, we measured serum levels of total bilirubin, alanine transaminase (ALT) and aspartate transaminase (AST) using ELISA (Sigma Aldrich, St. Louis, MO). Serum cholesterol levels were measured using the Infinity Cholesterol Liquid Stable Reagent (Thermo Electron Corp., Waltham, MA) and serum testosterone levels were measured by ELISA (R\&D systems, Minneapolis, MN). Androgen concentrations were measured in flash frozen prostate tissue from 4 month old mice using mass spectrometry, as previously described. ${ }^{21}$

\section{Statistical analyses}

Differences in body and prostate weights, serum cholesterol levels and tumor proliferative and apoptotic indexes between dietary groups were examined using Student's $\mathrm{t}$ tests. Linear regression was used to examine the relationship between serum cholesterol levels and body and prostate weight, tumor proliferative and apoptotic indexes, and serum and prostate androgen levels. Statistical analysis was carried out using STATA 13.0 (Stata, Corp., College Station, TX, USA). Statistical significance was two-sided with $p<0.05$. 


\section{Results}

Effect of serum cholesterol reduction on caloric intake and body weight

Caloric intake did not differ between dietary groups (Figure 1A), and there were no differences in body weights between dietary groups at randomization (HFHC vs. Zetia; $17.3 \mathrm{~g}$ vs. $17.6 \mathrm{~g}$, $\mathrm{p}=0.800$ ) or at 4 month sacrifice (HFHC; $36.6 \mathrm{~g}$ vs. Zetia; $36.2 \mathrm{~g}, \mathrm{p}=0.767$; Figure 1B, C). However, inhibition of cholesterol uptake resulted in significantly reduced serum cholesterol levels by 4 months of age (Zetia vs. HFHC; $161 \mathrm{mg} / \mathrm{dl}$ vs. $201 \mathrm{mg} / \mathrm{dl}$, respectively; $p=0.031$; Figure 1C). Serum cholesterol level was not significantly correlated with body weight at sacrifice (Figure 1D). There were no differences between dietary groups with respect to liver and spleen size (all $p>0.1$; Supplementary Figure S1) or liver function (all $p>0.1$; Supplementary Figure S2).

\section{Effect of serum cholesterol reduction on prostate tumor development and growth}

Prostate weight was slightly, but not significantly, reduced in the Zetia group $(0.39 \mathrm{~g}$ vs. $0.45 \mathrm{~g}$; $p=0.275$; Figure $2 \mathrm{~A}$ ). However, as a continuous variable, higher serum cholesterol was significantly positively correlated with larger prostate size $(p=0.033$; Figure $2 B)$.

In order to examine the effect of reducing serum cholesterol levels on prostate cancer development, we classified prostate histology as normal, mPIN, invasive adenocarcinoma or intracystic adenocarcinoma, according to current guidelines. ${ }^{22}$ By 4 months of age, all mice had developed both invasive and intracystic adenocarcinoma (Table 1), regardless of dietary group. The rate of development of invasive or intracystic adenocarcinoma did not vary significantly by dietary group (Table 1).

Effect of serum cholesterol on prostate tumor proliferation and apoptosis

We used an automated digital pathology approach to quantify rates of proliferation and apoptosis in the tumor epithelium and tumor stroma separately, excluding areas of normal 
prostate tissue, necrosis and fluid-filled intracystic lesions (Supplementary Figures S3, S4, S5). We found that mice randomized to the Zetia diet had lower tumor epithelial proliferation than those randomized to $\mathrm{HFHC}$ at 4 months of age (Ki67 H score 19.6 vs. 25.4; $\mathrm{p}=0.173$; Figure 3), although this association was not significant. There was no difference in tumor epithelial apoptosis scores between dietary groups $(p=0.528)$. When serum cholesterol was examined as a continuous variable, there was a positive correlation between high serum cholesterol levels and increased tumor epithelial cell proliferation at 4 months $(p=0.069)$, although this was not statistically significant, and a negative correlation between high serum cholesterol levels and tumor epithelial cell apoptosis ( $p=0.004$; Figure 3 ). Restricting our analysis to the tumor stroma revealed that mice consuming Zetia diet had significantly reduced tumor stromal proliferation $(p=0.010)$, although rates of tumor stromal cell apoptosis did not differ between dietary groups $(p=0.723$; Supplementary Figure S6). However, serum cholesterol levels were significantly inversely correlated with tumor stromal cell apoptosis at 4 months $(p=0.048)$, although the positive correlation between serum cholesterol levels and stromal proliferation was not significant $(p=0.328$; Supplementary Figure $S 6)$. We investigated whether serum cholesterol levels modified tumor composition by quantifying the proportion of stromal tissue within the tumor, and found no significant differences between dietary groups (data not shown).

\section{Effect of serum cholesterol levels on serum and prostate androgen concentrations}

Levels of serum and prostate androgens did not differ between dietary groups at 4 months of age (data not shown). However, levels of prostate testosterone, DHT, DHEA and androstenedione were positively correlated with serum cholesterol levels, although these associations were not significant (Table 2). Adjusting linear regression analyses for age at dietary randomization strengthened these associations, particularly for DHEA and androstenedione $(p=0.043$ and $p=0.031$, respectively). Serum testosterone levels were positively correlated with serum cholesterol levels at 4 months, and this association was 
strengthened after adjusting for age at dietary randomization ( $p=0.077$; Table 2$)$, though it remained not significant. 


\section{Discussion}

Obesity, a common disorder affecting approximately one third of US men, ${ }^{23}$ is associated with increased incidence of aggressive prostate cancer and elevated prostate cancer mortality. ${ }^{1}$ While the association between obesity and prostate cancer is likely multifactorial, epidemiologic and preclinical evidence indicates a potential role for high cholesterol, an obesity-associated metabolic abnormality, in prostate cancer progression, ${ }^{24}$ though not all studies have found a link between cholesterol and prostate cancer. ${ }^{7}$ Using an obese PTEN-null transgenic mouse model of prostate cancer, we show that lowering serum cholesterol levels reduced tumor proliferation, increased tumor apoptosis, lowered tumor androgen concentrations and slowed prostate tumor growth. In contrast, we found that serum cholesterol reduction did not significantly affect the rate of adenocarcinoma development. Though our findings do not support a role for cholesterol lowering in slowing tumor development in the PTEN-null mouse model of prostate cancer, they do provide evidence for an effect of serum cholesterol on tumor androgen signaling and tumor growth. Future studies are needed to determine the potential role for cholesterol-lowering interventions in prostate cancer treatment.

Since the recognition of prostate cancer as an androgen-dependent disease,${ }^{25}$ targeting the androgen signaling pathway has been the mainstay of advanced prostate cancer treatment. While the disease is initially responsive to androgen-deprivation therapy, the majority of patients eventually go on to develop castration-resistant prostate cancer (CRPC), which is currently incurable. There is substantial evidence that achieving castrate levels of circulating androgens does not eliminate intraprostatic androgens, and that intratumoral de novo androgen synthesis from cholesterol may be an important source of these residual tumor androgens in castrate men. ${ }^{26,27}$ Indeed, statin use and lower cholesterol levels have been associated with lower levels of PSA, ${ }^{28,29}$ whose gene is under the control of the androgen receptor, suggesting that cholesterol reduction may impact intraprostatic androgen signaling. Furthermore, some 
epidemiologic evidence supports a potential role for serum cholesterol level in response to androgen deprivation therapy. One study reported a shorter time to castrate-resistant prostate cancer development in men with elevated serum cholesterol levels at the time of androgen deprivation therapy, relative to those with normal cholesterol. ${ }^{30}$ Another study demonstrated that statin use at initiation of androgen deprivation therapy delayed progression to castrate-resistant prostate cancer. ${ }^{31}$ In the present study, we demonstrate that reduction of serum cholesterol levels in a mouse model of prostate cancer decreased intratumoral androgen concentrations, adding support to epidemiologic and laboratory data that cholesterol-lowering strategies should potentially be explored alongside androgen-deprivation therapy in prostate cancer.

This study should be considered in light of its limitations. Although statins are the most commonly prescribed cholesterol-lowering drugs in the clinic, they do not reduce serum cholesterol levels in mice. ${ }^{32}$ As such, we achieved cholesterol reduction in our mouse model using the FDA-approved drug, ezetimibe, usually prescribed to human patients in conjunction with a statin or as a substitute in patients that cannot tolerate a statin. However, given the hepato-selectivity and low systemic bioavailability of statins, it may be that their effects on the prostate are predominantly mediated indirectly via reduction of systemic cholesterol levels. ${ }^{33}$ Furthermore, the use of ezetimibe in the present study enabled examination of the effect of cholesterol reduction on prostate cancer growth in the absence of changes to dietary composition and/or obesity status, both of which have been implicated in prostate cancer. ${ }^{1,34}$ Future studies should explore the effect of statin use and serum cholesterol reduction on intratumoral androgen signaling in humans. Regarding our tumor growth measurements, we could not assess the contribution of fluid-filled intracystic lesions to tumor weight, and this may bias our results. However, our finding that lowering serum cholesterol slowed tumor growth is also supported by our observation of decreased tumor cell proliferation and increased tumor cell apoptosis in mice with lower cholesterol levels, as determined by IHC assays. These limitations 
are balanced by an important strength of this study. Loss of the tumor suppressor, PTEN, is one of the most common genetic alterations in prostate cancer, ${ }^{20}$ making this a relevant mouse model with which to study this disease. In addition, the use of a transgenic mouse model enabled assessment of the effect of cholesterol reduction on prostate cancer growth within the native microenvironment, known to play a role in disease progression. ${ }^{35}$

Cardiovascular disease and cancer are leading causes of mortality in Western society, ${ }^{36}$ and prostate cancer is the second most common cause of male cancer deaths in the US. ${ }^{37}$ Therefore, understanding the role of hypercholesterolemia as a shared risk factor for these diseases has great public health importance. Furthermore, high cholesterol is a readily modifiable risk factor through the use of pharmaceutical agents and/or lifestyle modifications. Notably, we demonstrate that cholesterol reduction affects prostate cancer growth even within the context of diet-induced obesity, a known prostate cancer promoter. Together with epidemiologic evidence suggesting a potential role for hypercholesterolemia in promoting prostate cancer progression, ${ }^{8,10}$ and for statins in preventing aggressive prostate cancer incidence and progression, ${ }^{13-15}$ these results support further studies exploring a role for cholesterol-lowering interventions in prostate cancer treatment.

Conflicts of interest: The authors have no conflicts of interest. 


\section{References}

1. Allott EH, Masko EM, Freedland SJ. Obesity and prostate cancer: weighing the evidence. European urology 2013; 63(5): 800-809.

2. Fryar CD, Chen TC, Li X. Prevalence of uncontrolled risk factors for cardiovascular disease: United States, 1999-2010. NCHS data brief 2012;(103): 1-8.

3. Platz EA, Till C, Goodman PJ, Parnes HL, Figg WD, Albanes D et al. Men with low serum cholesterol have a lower risk of high-grade prostate cancer in the placebo arm of the prostate cancer prevention trial. Cancer Epidemiol Biomarkers Prev 2009; 18(11): 2807-2813.

4. Mondul AM, Weinstein SJ, Virtamo J, Albanes D. Serum total and HDL cholesterol and risk of prostate cancer. Cancer causes \& control : CCC 2011; 22(11): 1545-1552.

5. Shafique K, McLoone P, Qureshi K, Leung H, Hart C, Morrison DS. Cholesterol and the risk of grade-specific prostate cancer incidence: evidence from two large prospective cohort studies with up to 37 years' follow up. BMC cancer 2012; 12: 25.

6. Farwell WR, D'Avolio LW, Scranton RE, Lawler EV, Gaziano JM. Statins and prostate cancer diagnosis and grade in a veterans population. Journal of the National Cancer Institute 2011; 103(11): 885-892.

7. YuPeng L, YuXue Z, PengFei L, Cheng C, YaShuang Z, DaPeng L et al. Cholesterol Levels in Blood and the Risk of Prostate Cancer: A Meta-analysis of 14 Prospective Studies. Cancer Epidemiol Biomarkers Prev 2015.

8. Allott EH, Howard LE, Cooperberg MR, Kane CJ, Aronson WJ, Terris MK et al. Serum Lipid Profile and Risk of Prostate Cancer Recurrence: Results from the SEARCH Database. Cancer Epidemiol Biomarkers Prev 2014; 23(11): 2349-2356.

9. Gutt R, Tonlaar N, Kunnavakkam R, Karrison T, Weichselbaum RR, Liauw SL. Statin use and risk of prostate cancer recurrence in men treated with radiation therapy. $J$ Clin Oncol 2010; 28(16): 2653-2659.

10. Batty GD, Kivimaki M, Clarke R, Davey Smith G, Shipley MJ. Modifiable risk factors for prostate cancer mortality in London: forty years of follow-up in the Whitehall study. Cancer causes \& control : CCC 2011; 22(2): 311-318.

11. Ohno Y, Ohori M, Nakashima J, Okubo H, Satake N, Hashimoto T et al. Association between preoperative serum total cholesterol level and biochemical recurrence in 
prostate cancer patients who underwent radical prostatectomy. Mol Clin Oncol 2016; 4(6): 1073-1077.

12. Wettstein MS, Saba K, Umbehr MH, Murtola TJ, Fankhauser CD, Adank JP et al. Prognostic Role of Preoperative Serum Lipid Levels in Patients Undergoing Radical Prostatectomy for Clinically Localized Prostate Cancer. The Prostate 2017; 77(5): 549556.

13. Bansal D, Undela K, D'Cruz S, Schifano F. Statin use and risk of prostate cancer: a meta-analysis of observational studies. PloS one 2012; 7(10): e46691.

14. Allott EH, Howard LE, Cooperberg MR, Kane CJ, Aronson WJ, Terris MK et al. Postoperative statin use and risk of biochemical recurrence following radical prostatectomy: results from the Shared Equal Access Regional Cancer Hospital (SEARCH) database. BJU international 2014.

15. Yu O, Eberg M, Benayoun S, Aprikian A, Batist G, Suissa S et al. Use of statins and the risk of death in patients with prostate cancer. J Clin Oncol 2014; 32(1): 5-11.

16. Alfaqih MA, Allott EH, Hamilton RJ, Freeman MR, Freedland SJ. The current evidence on statin use and prostate cancer prevention: are we there yet? Nature reviews Urology 2017; 14(2): 107-119.

17. Krycer JR, Brown AJ. Cholesterol accumulation in prostate cancer: a classic observation from a modern perspective. Biochimica et biophysica acta 2013; 1835(2): 219-229.

18. Mostaghel EA, Solomon KR, Pelton K, Freeman MR, Montgomery RB. Impact of circulating cholesterol levels on growth and intratumoral androgen concentration of prostate tumors. PloS one 2012; 7(1): e30062.

19. Solomon KR, Pelton K, Boucher K, Joo J, Tully C, Zurakowski D et al. Ezetimibe is an inhibitor of tumor angiogenesis. Am J Pathol 2009; 174(3): 1017-1026.

20. Wang S, Gao J, Lei Q, Rozengurt N, Pritchard C, Jiao J et al. Prostate-specific deletion of the murine Pten tumor suppressor gene leads to metastatic prostate cancer. Cancer cell 2003; 4(3): 209-221.

21. Page ST, Kalhorn TF, Bremner WJ, Anawalt BD, Matsumoto AM, Amory JK. Intratesticular androgens and spermatogenesis during severe gonadotropin suppression induced by male hormonal contraceptive treatment. Journal of andrology 2007; 28(5): 734-741. 
22. Ittmann M, Huang J, Radaelli E, Martin P, Signoretti S, Sullivan R et al. Animal models of human prostate cancer: the consensus report of the New York meeting of the Mouse Models of Human Cancers Consortium Prostate Pathology Committee. Cancer Res 2013; 73(9): 2718-2736.

23. Flegal KM, Carroll MD, Kit BK, Ogden CL. Prevalence of obesity and trends in the distribution of body mass index among US adults, 1999-2010. JAMA 2012; 307(5): 491497.

24. Masko EM, Allott EH, Freedland SJ. The relationship between nutrition and prostate cancer: is more always better? European urology 2013; 63(5): 810-820.

25. Huggins C, Hodges CV. Studies on prostatic cancer. I. The effect of castration, of estrogen and androgen injection on serum phosphatases in metastatic carcinoma of the prostate. CA: a cancer journal for clinicians 1972; 22(4): 232-240.

26. Mostaghel EA, Plymate SR, Montgomery B. Molecular pathways: targeting resistance in the androgen receptor for therapeutic benefit. Clin Cancer Res 2014; 20(4): 791-798.

27. Locke JA, Guns ES, Lubik AA, Adomat HH, Hendy SC, Wood CA et al. Androgen levels increase by intratumoral de novo steroidogenesis during progression of castrationresistant prostate cancer. Cancer Res 2008; 68(15): 6407-6415.

28. Hamilton RJ, Goldberg KC, Platz EA, Freedland SJ. The influence of statin medications on prostate-specific antigen levels. Journal of the National Cancer Institute 2008; 100(21): 1511-1518.

29. Zapata D, Howard LE, Allott EH, Hamilton RJ, Goldberg K, Freedland SJ. Is PSA related to serum cholesterol and does the relationship differ between black and white men? The Prostate 2015; 75(16): 1877-1885.

30. Jeon JC, Park J, Park S, Moon KH, Cheon SH, Park S. Hypercholesterolemia Is Associated with a Shorter Time to Castration-Resistant Prostate Cancer in Patients Who Have Undergone Androgen Deprivation Therapy. World J Mens Health 2016; 34(1): 2833.

31. Harshman LC, Wang X, Nakabayashi M, Xie W, Valenca L, Werner L et al. Statin Use at the Time of Initiation of Androgen Deprivation Therapy and Time to Progression in Patients With Hormone-Sensitive Prostate Cancer. JAMA Oncol 2015; 1(4): 495-504.

32. Pelton K, Freeman MR, Solomon KR. Cholesterol and prostate cancer. Current opinion in pharmacology 2012. 
33. Sirtori CR. Tissue selectivity of hydroxymethylglutaryl coenzyme A (HMG CoA) reductase inhibitors. Pharmacology \& therapeutics 1993; 60(3): 431-459.

34. Masko EM, Allott EH, Freedland SJ. The Relationship Between Nutrition and Prostate Cancer: Is More Always Better? European urology 2012.

35. Nieto CM, Rider LC, Cramer SD. Influence of stromal-epithelial interactions on androgen action. Endocrine-related cancer 2014; 21(4): T147-160.

36. His M, Zelek L, Deschasaux M, Pouchieu C, Kesse-Guyot E, Hercberg S et al. Prospective associations between serum biomarkers of lipid metabolism and overall, breast and prostate cancer risk. European journal of epidemiology 2014.

37. Siegel RL, Miller KD, Jemal A. Cancer Statistics, 2018. CA: a cancer journal for clinicians 2018 (in press) 


\section{Figure legends}

Figure 1: Caloric intake $(A)$ and body weight $(B)$ trajectories throughout the study duration in the PTEN-null transgenic mouse model of prostate cancer, median differences in serum cholesterol level between dietary groups at 4 months of age (C), and correlation between body weight at 4 months of age and serum cholesterol levels (D).

Figure 2: Effect of serum cholesterol reduction on prostate weight at 4 months of age in the PTEN-null transgenic mouse model

Figure 3: Effect of cholesterol reduction on proliferation and apoptosis in prostate tumor epithelium at 4 months of age in the PTEN-null transgenic mouse model

A

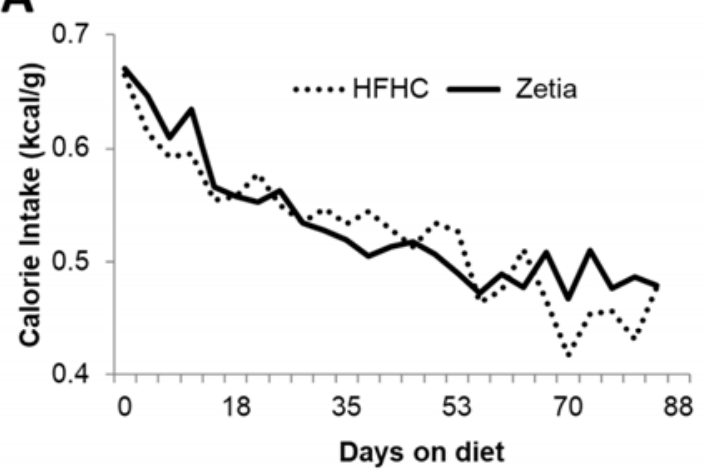

\section{C}

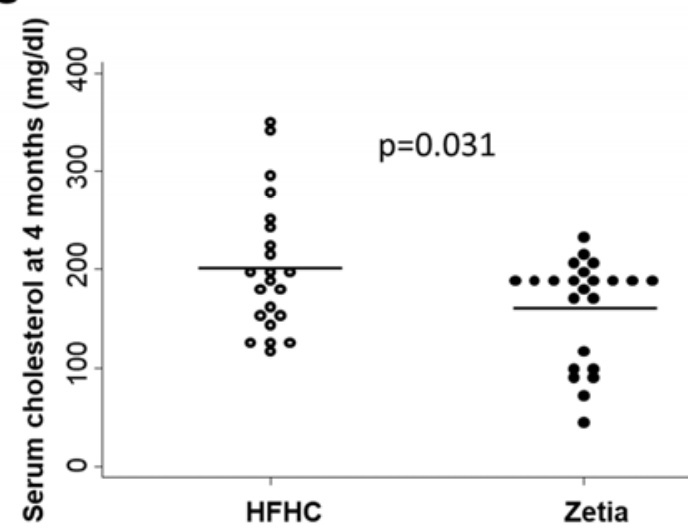

B

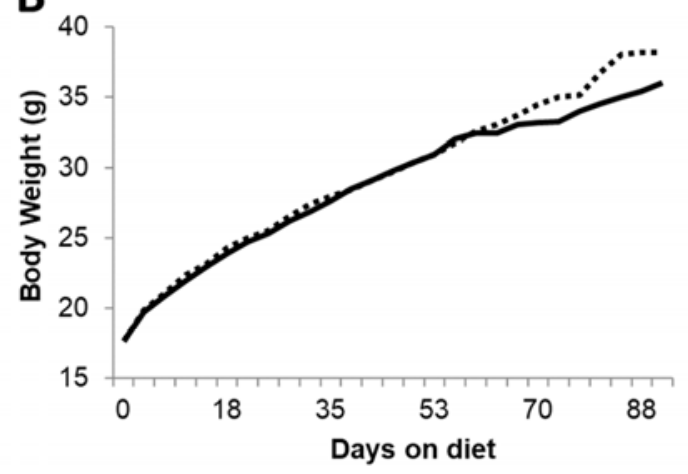

D

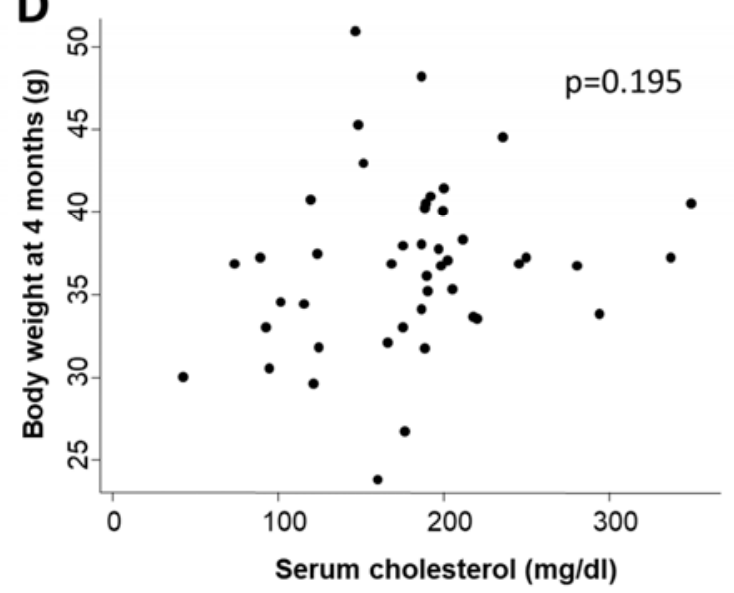


Figure 1: Caloric intake (A) and body weight (B) trajectories throughout the study duration in the PTENnull transgenic mouse model of prostate cancer, median differences in serum cholesterol level between dietary groups at 4 months of age (C), and correlation between body weight at 4 months of age and serum cholesterol levels (D).

A

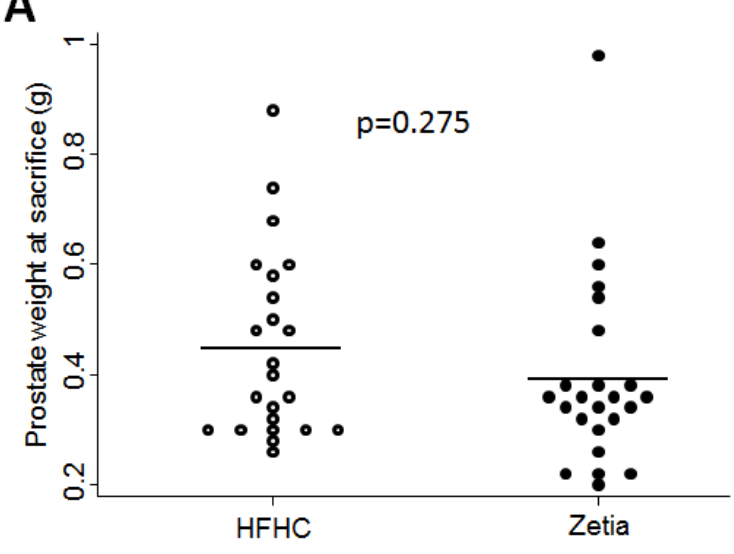

B

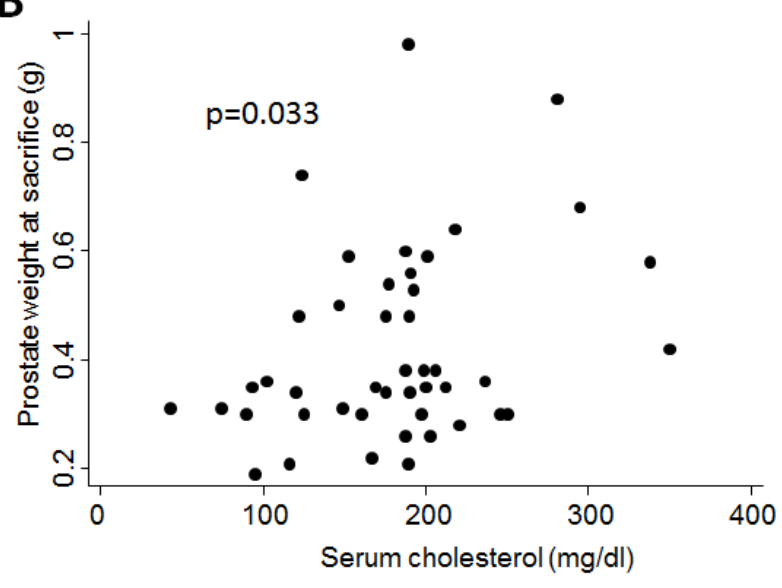

Figure 2: Effect of serum cholesterol reduction on prostate weight at 4 months of age in the PTEN-null transgenic mouse model 

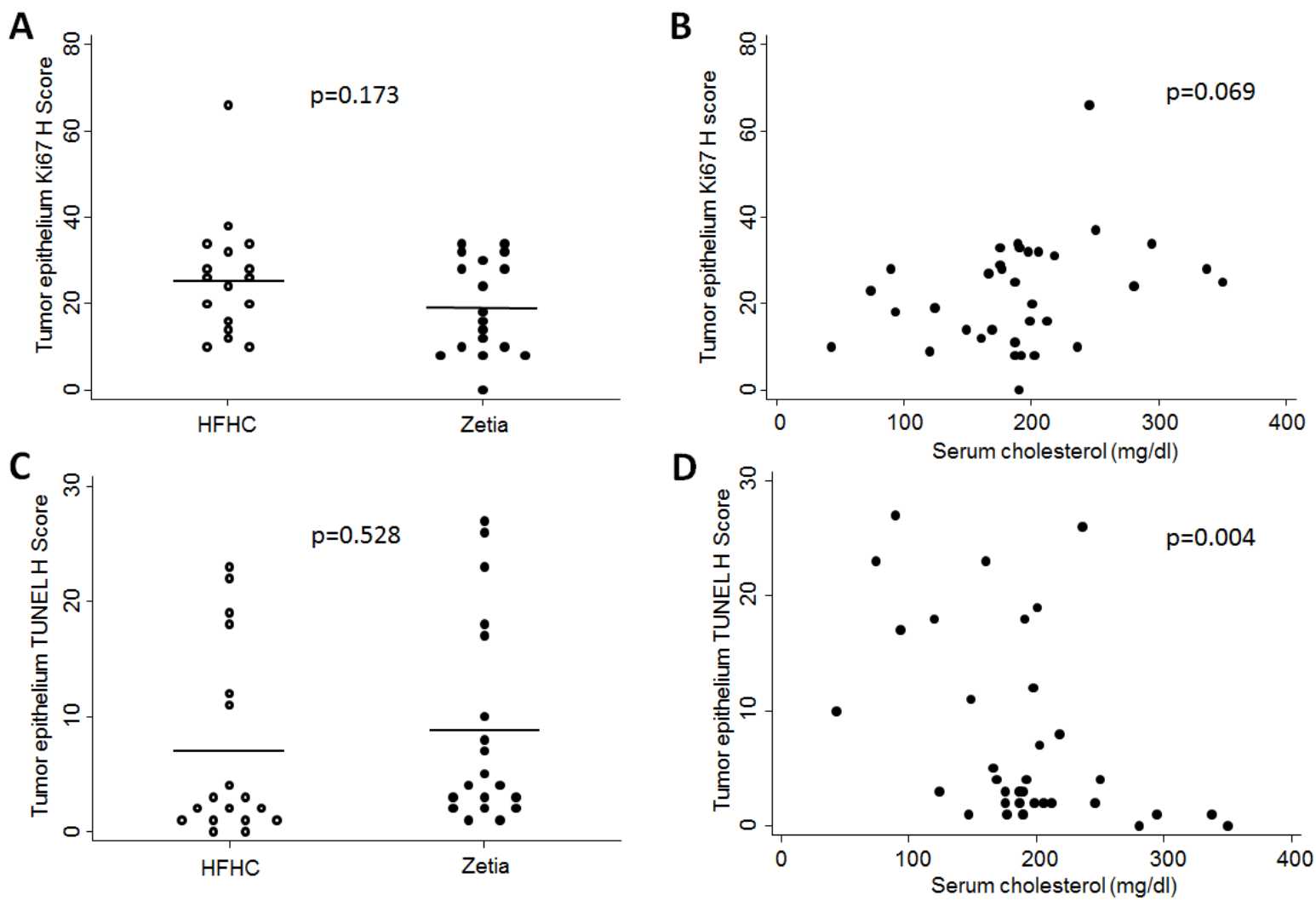

Figure 3: Effect of cholesterol reduction on proliferation and apoptosis in prostate tumor epithelium at 4 months of age in the PTEN-null transgenic mouse model 
Table 1: Effect of lowering serum cholesterol levels on prostate tumor progression in the PTEN-null transgenic mouse model

\begin{tabular}{|c|c|c|c|c|c|c|}
\hline & \multicolumn{2}{|c|}{2 months of age } & \multicolumn{2}{c|}{3 months of age } & \multicolumn{2}{|c|}{ 4 months of age } \\
\hline & $\begin{array}{c}\text { Invasive } \\
\text { adeno- } \\
\text { carcinoma, } \\
\text { n (\%) }\end{array}$ & $\begin{array}{c}\text { Intracystic } \\
\text { adeno- } \\
\text { carcinoma, } \\
\mathbf{n}(\%)\end{array}$ & $\begin{array}{c}\text { Invasive } \\
\text { adeno- } \\
\text { carcinoma, } \\
\mathbf{n}(\%)\end{array}$ & $\begin{array}{c}\text { Intracystic } \\
\text { adeno- } \\
\text { carcinoma, } \\
\text { n (\%) }\end{array}$ & $\begin{array}{c}\text { Invasive } \\
\text { adeno- } \\
\text { carcinoma, } \\
\text { n (\%) }\end{array}$ & $\begin{array}{c}\text { Intracystic } \\
\text { adeno- } \\
\text { carcinoma, } \\
\text { n (\%) }\end{array}$ \\
\hline HFHC & $0(0)$ & $1(14)$ & $7(78)$ & $4(44)$ & $23(100)$ & $23(100)$ \\
\hline Zetia & $0(0)$ & $0(0)$ & $8(80)$ & $3(30)$ & $25(100)$ & $25(100)$ \\
\hline
\end{tabular}

Table 2: Correlation between serum cholesterol levels and serum and prostate androgens at 4 months of age in the PTEN-null transgenic mouse model

\begin{tabular}{|l|c|c|c|c|}
\hline & $\beta$ coefficient (95\% Cl)* & $p$ value* & $\beta$ coefficient $(95 \% \mathrm{Cl})^{* *}$ & $p$ value** \\
\hline Serum levels & & & & \\
Pestosterone & $0.017(-0.022,0.057)$ & 0.358 & $0.036(-0.005,0.076)$ & 0.077 \\
Testosterone & $0.020(-0.010,0.050)$ & 0.169 & $0.027(-0.003,0.058)$ & 0.074 \\
DHT & $0.007(-0.014,0.029)$ & 0.447 & $0.013(-0.007,0.033)$ & 0.179 \\
DHEA & $0.003(-0.001,0.007)$ & 0.165 & $0.004(0.000,0.008)$ & 0.043 \\
Androstendione & $0.001(-0.0002,0.003)$ & 0.095 & $0.002(0.0002,0.0034)$ & 0.031 \\
\hline
\end{tabular}

DHEA; dehydroepiandrosterone, DHT; dihydrotestosterone

$P$ values obtained by linear regression

*unadjusted

**adjusted for age at dietary randomization 
Supplementary Data

Supplementary Table S1: Formulation of diets used in the current study

\begin{tabular}{|c|c|c|}
\hline Research Diets Formula & $\begin{array}{l}\text { High fat high cholesterol } \\
\text { (HFHC), D09062501 }\end{array}$ & $\begin{array}{c}\text { High fat high cholesterol + Zetia } \\
\text { (Zetia), D09062502 }\end{array}$ \\
\hline & \multicolumn{2}{|c|}{ g\% (kcal\%) } \\
\hline Protein & $20(17)$ & $20(17)$ \\
\hline Carbohydrate & $49(43)$ & $49(43)$ \\
\hline Fat & $21(40)$ & $21(40)$ \\
\hline \multirow[t]{2}{*}{$\mathrm{kcal} / \mathrm{g}$} & 4.6 & 4.6 \\
\hline & \multicolumn{2}{|c|}{$g$} \\
\hline Casein & 195 & 195 \\
\hline DL-Methionine & 3 & 3 \\
\hline Corn starch & 50 & 50 \\
\hline Maltodextrin 10 & 100 & 100 \\
\hline Sucrose & 341 & 341 \\
\hline Cellulose, BW200 & 50 & 50 \\
\hline Milk fat & 200 & 200 \\
\hline Corn oil & 10 & 10 \\
\hline Mineral Mix S10001 & 35 & 35 \\
\hline Calcium Carbonate & 4 & 4 \\
\hline Vitamin Mix V10001 & 10 & 10 \\
\hline Choline Bitartrate & 2 & 2 \\
\hline Cholesterol & 12.05 & 12.05 \\
\hline Ethoxyquin & 0.04 & 0.04 \\
\hline
\end{tabular}




\begin{tabular}{|c|c|c|}
\hline FD\&C Red Dye \#40 & 0 & 0.05 \\
\hline FD\&C Yellow Dye \#5 & 0.05 & 0 \\
\hline Total & 1012.14 & 1012.14 \\
\hline Cholesterol (\%) & 1.25 & 30 \\
\hline Ezetimibe (mg/kg) & 0 & 30 \\
\hline
\end{tabular}
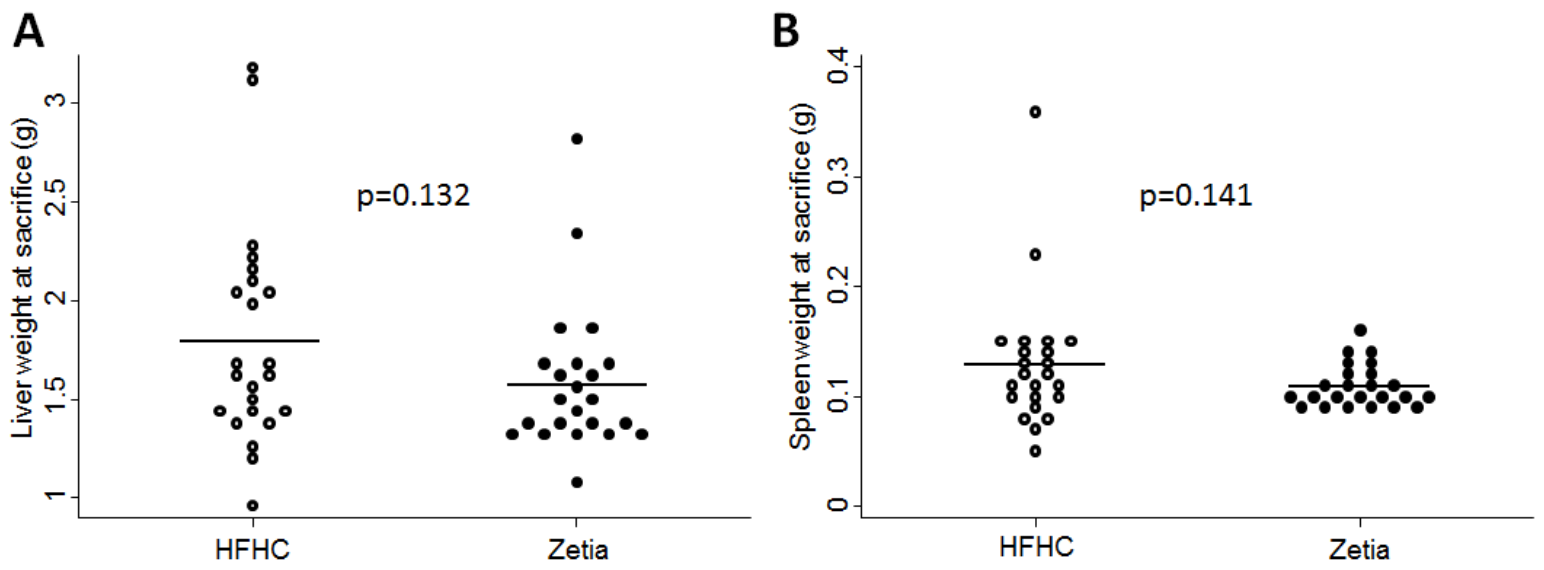

Supplementary Figure S1: Effect of serum cholesterol reduction on liver and spleen size at 4 months of age in the PTEN-null transgenic mouse model
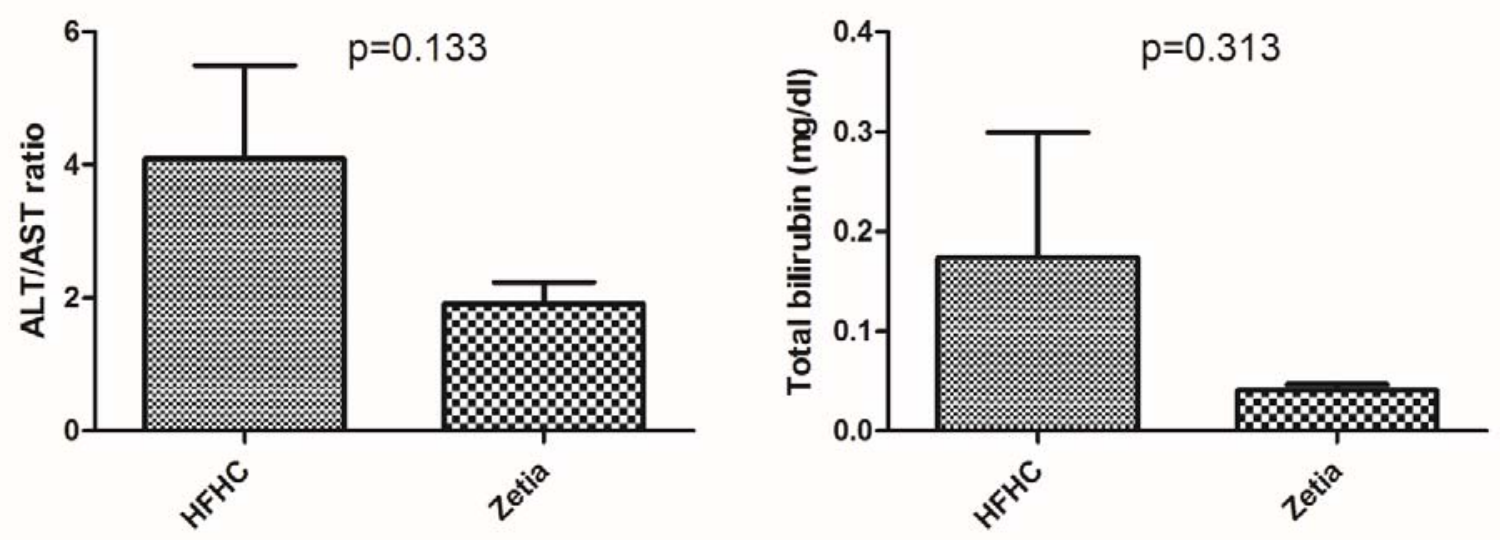
Supplementary Figure S2: Effect of serum cholesterol reduction on liver function at 4 months of age in the PTEN-null transgenic mouse model 

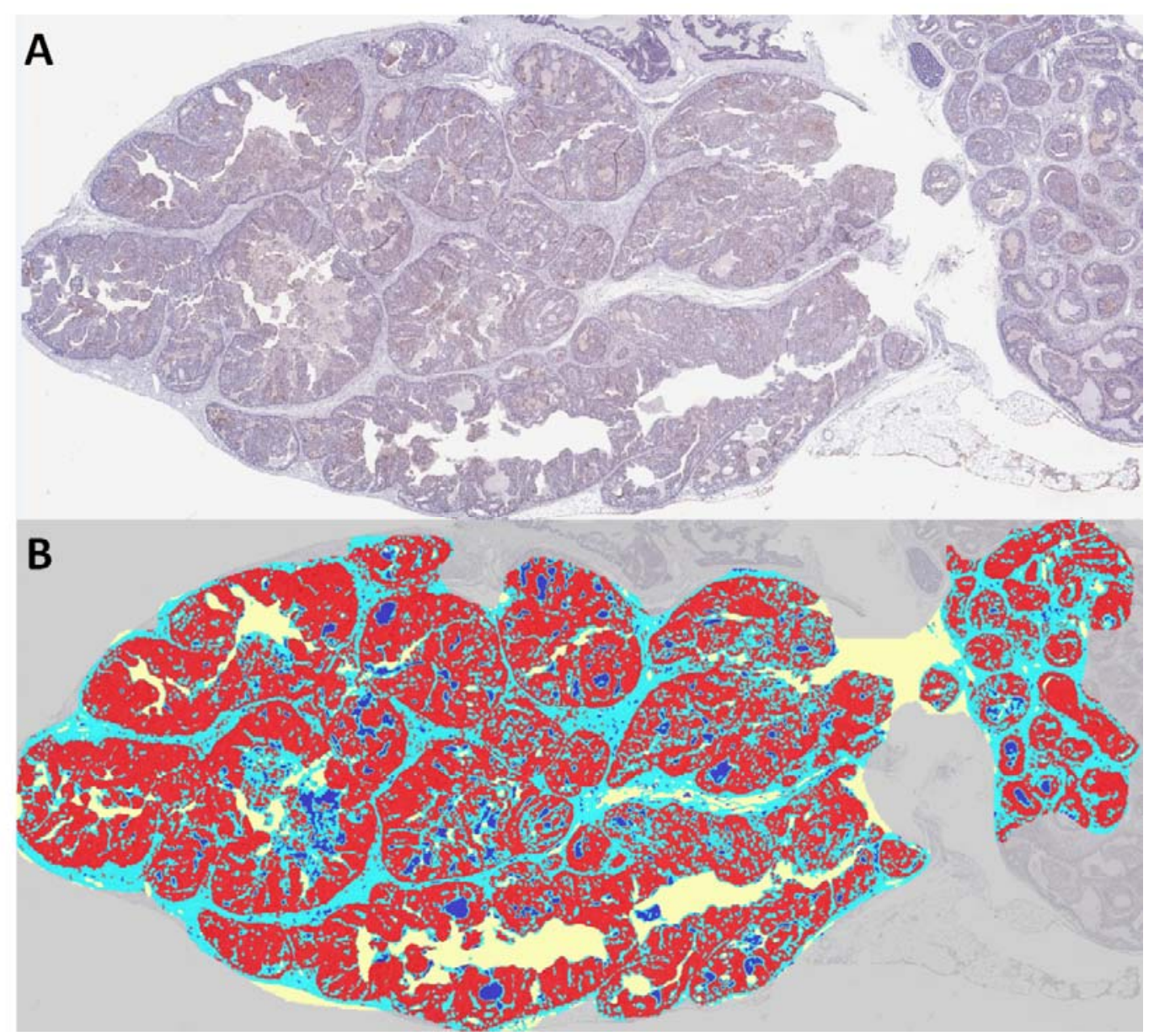

Supplementary Figure S3: Definiens Tissue Studio algorithm to separate epithelium from stroma

Legend: Prostate gland stained for TUNEL (A), and processed by Aperio algorithm to differentiate tissue types (B); Red=epithelium; dark blue=necrosis; light blue=stroma; yellow=glass; grey=area manually excluded from analysis 

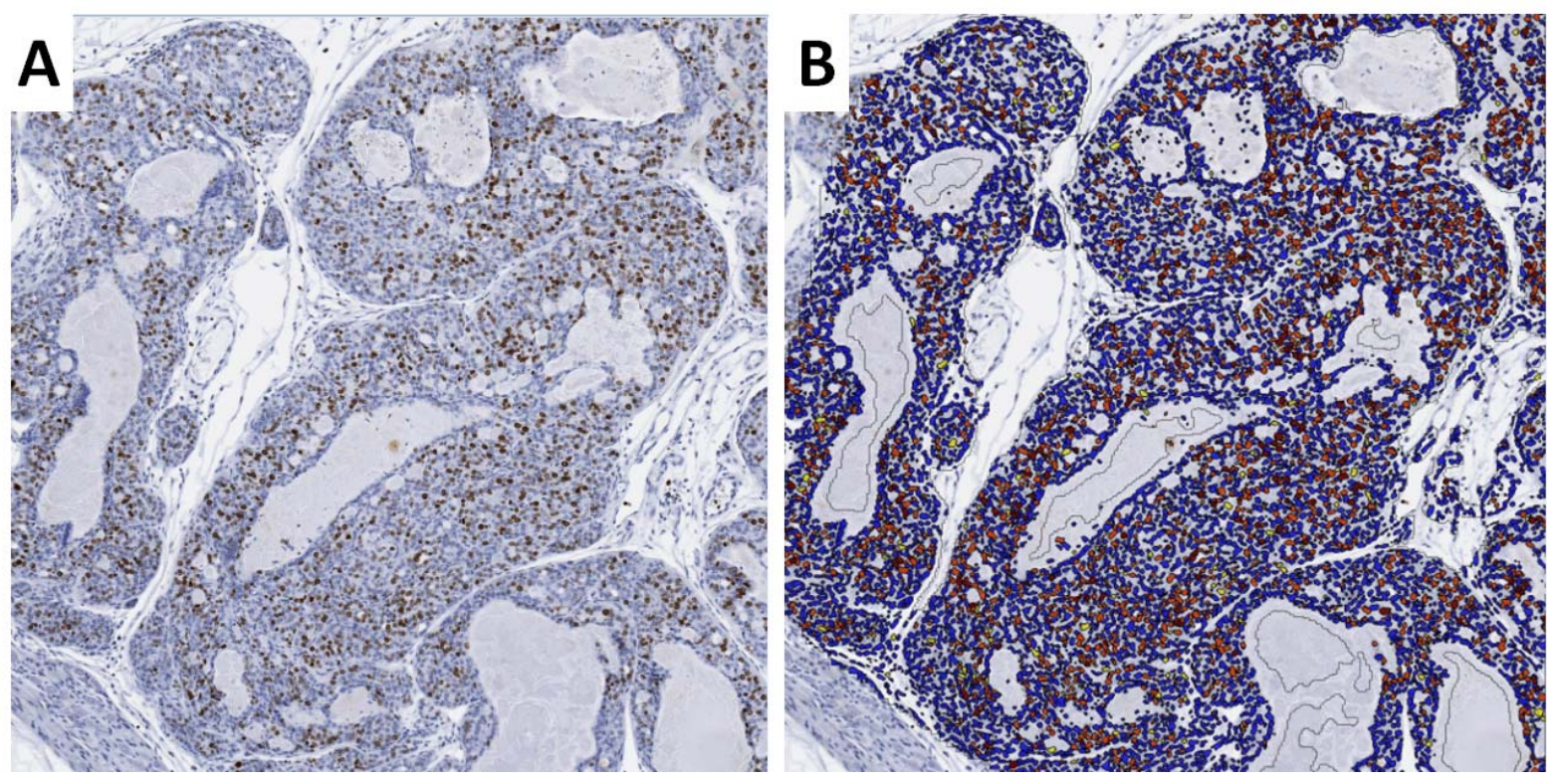

Supplementary Figure S4: Quantification of tumor epithelial staining using Definiens Tissue Studio

Legend: Blue=negative nuclei; Yellow/Orange/Red=positive nuclei with increasing staining intensity Note exclusion of stromal and necrotic areas of tissue by the algorithm 


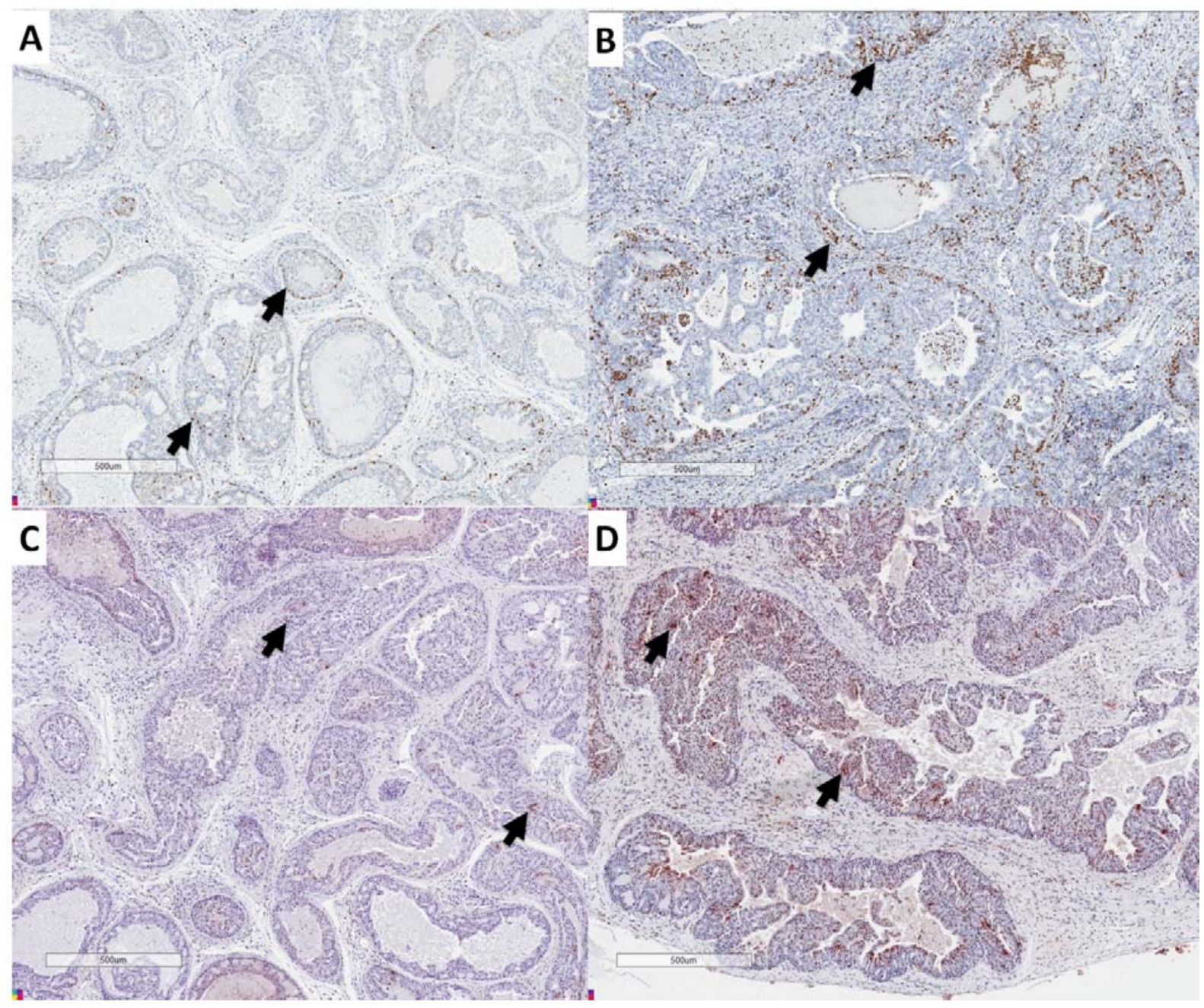

Supplementary Figure S5: Representative images of low and high Ki67 staining ( $A$ and B, respectively) and low and high TUNEL staining ( $C$ and $D$, respectively) at 4 months of age in the PTEN-null transgenic mouse model 
A

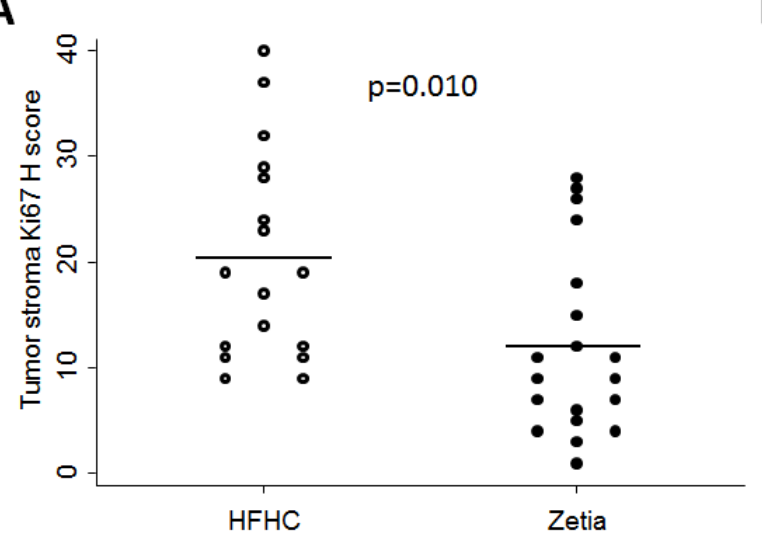

C

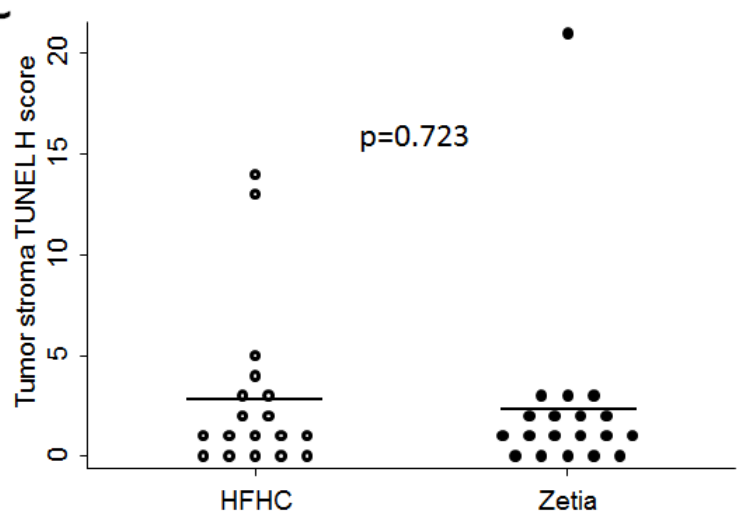

B
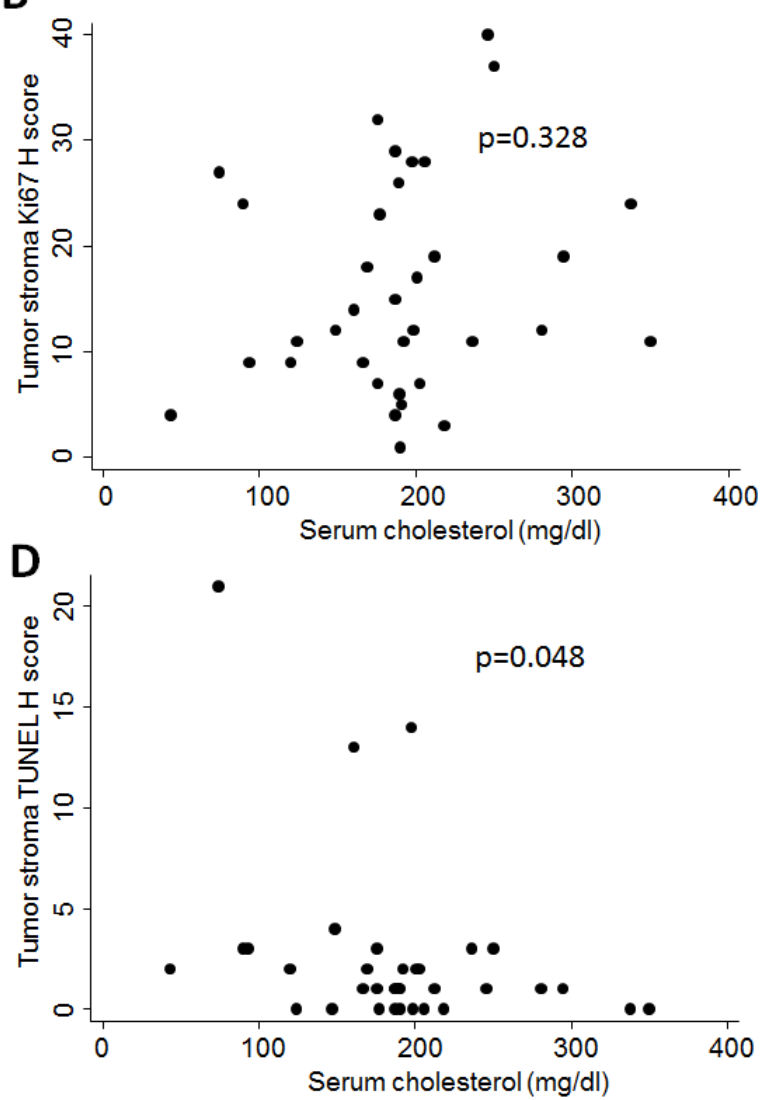

Supplementary Figure S6: Effect of cholesterol reduction on proliferation and apoptosis in prostate tumor stroma at 4 months of age in the PTEN-null transgenic mouse model 